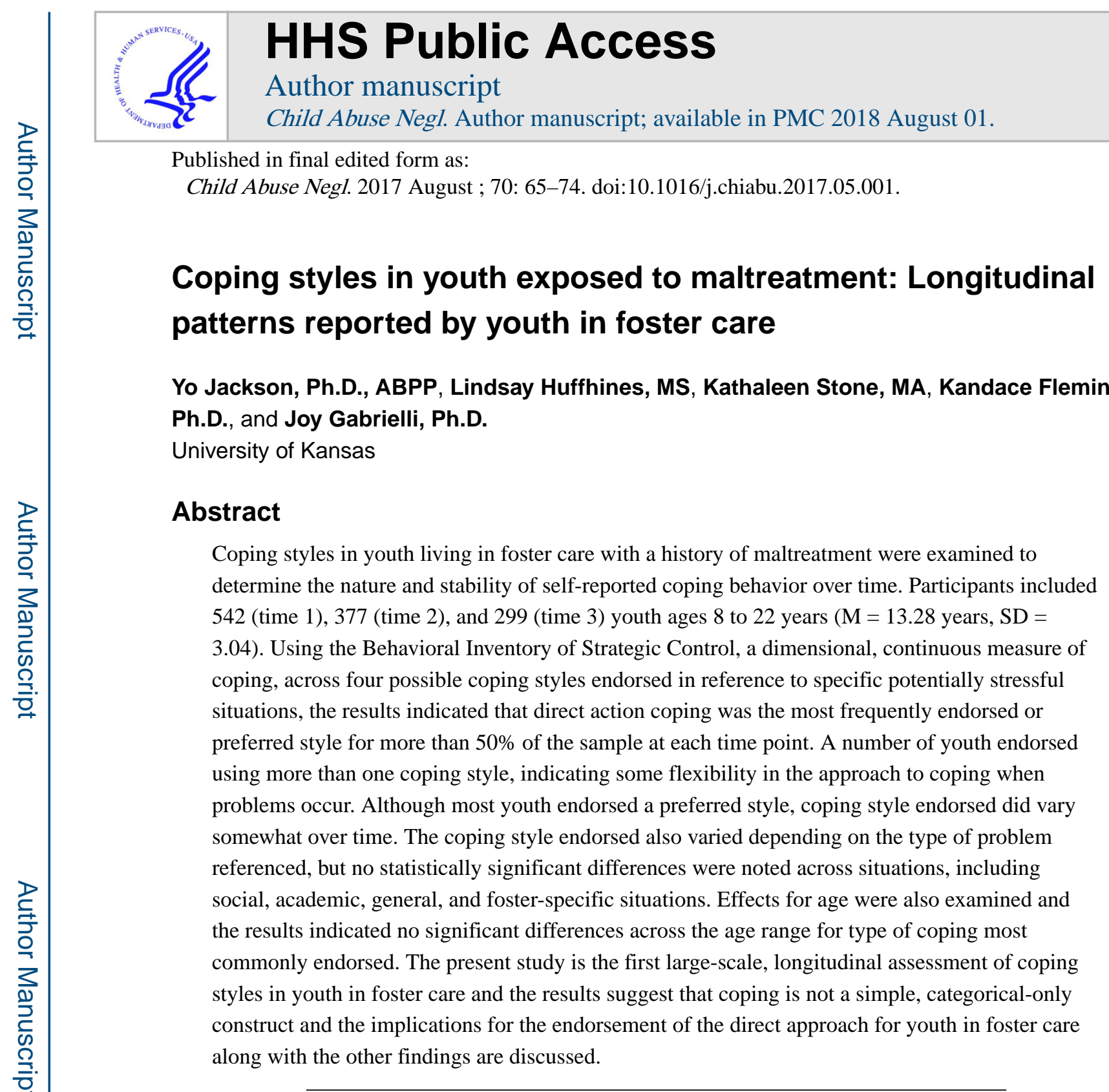

Determining how youth in foster care cope with stress is essential for understanding the impact of maltreatment and other adverse events on current and future adjustment and psychopathology (Compas, Connor-Simth, Saltzman, Harding Thomsen, \& Wadsworth, 2001). That is, the type of coping strategy employed may explain differences in adjustment among children who have been maltreated. For instance, Sesar, Šimić, and Barišić (2010) found that for youth with a history of child maltreatment, the use of emotion-focused coping predicted anxiety and depression symptoms, whereas the use of problem-focused coping strategies was negatively related to maladjustment in young adulthood.

Corresponding Author: Yo Jackson, Ph.D., ABPP, 1000 Sunnyside Ave., Room 2013, Lawrence, KS, 66045, yjackson@ku.edu. Publisher's Disclaimer: This is a PDF file of an unedited manuscript that has been accepted for publication. As a service to our customers we are providing this early version of the manuscript. The manuscript will undergo copyediting, typesetting, and review of the resulting proof before it is published in its final citable form. Please note that during the production process errors may be discovered which could affect the content, and all legal disclaimers that apply to the journal pertain. 
Although youth in foster care have likely had to cope with many more adverse life events than their non-foster care peers, relatively little attention has been paid in research to how youth in foster care cope with the various stressors they experience (Greer, 2011, Krattenmacher et al., 2013). Moreover, youth in foster care are a heterogeneous population of youth who vary not only in the kinds of experiences that lead to their placement in care, but also in the kinds of experiences they have while in care. Before clear links can be made between experiences and (mal)adjustment, it is important to document the kinds of coping this important population of youth endorse so that any relevant mental health outcomes found in other studies can be placed in context of the child's response style.

The present study did not seek to describe the function of the coping response (i.e., helpful or unhelpful), but rather, to address the gaps in the literature relative to youth in foster care to document (a) the kinds of coping strategies commonly reported by youth in foster care and, (b) to determine the stability of these coping approaches over time. Knowing how youth cope with events or the strategies they use when faced with a challenge is important for the field of foster care interventionists who often seek to provide youth methods to encourage mental health. By knowing which kinds of approaches youth tend to take in responding to events, the field will increase its basic understanding of how youth in foster care function beyond only documenting pathology, and thus potentially augment the effectiveness of interventions. The goal of the study was to provide the field with first-time evidence of the nature and consistency of coping styles for a large sample of youth in foster care.

\section{Conceptualizations of coping}

Lazarus and Folkman's (1984) adult model of stress, cognitive appraisal, and coping, has dominated the youth coping research literature, and provides an important historical context for the conceptualization and methodology of the current study. This widely-used approach defines coping as: "constantly changing cognitive and behavioral efforts to manage specific external and/or internal demands that are appraised as taxing or exceeding the resources of the person" (p. 141). The popular notions of problem-focused coping, or directing responses toward resolving the stressful relationship between the self and the environment, and emotion-focused coping, or working to alleviate the negative emotions that arise because stress, were derived from this model (Compas et al., 2001). Research indicates that in general, youth who endorse using emotion-focused coping tend to also have emotional instability and maladjustment (Carlo et al., 2012).

Most studies of youth coping commonly include highly specific samples (i.e., natural disasters, chronic illness) and findings may not generalize to samples of youth exposed to other kinds of nonnormative traumatic experiences like removal from biological caregivers. In a rare study of youth in foster care, Browne (2002) found that adolescents who had been abused were more likely to use emotion-focused - or nonproductive-coping than the adolescents with no maltreatment experience. Among adult survivors of child maltreatment, emotion-focused coping was significantly associated with physical health concerns (Hager \& Runtz, 2012). Although the two previous studies represent different samples, taken together, they suggest the potential for stability of an emotion focused coping approach over the lifespan. However, this common way of considering coping has been criticized as having 
too narrow of a focus (e.g., coping confined to one of two categories such as problem- or emotion- focused).

Expanding on Lazarus and Folkman's model (1984), Hobfoll, Dunahoo, Ben-Porath, and Monnier (1994) developed the Dual Axis Model of Coping to address this problem. This model suggests that coping strategies vary along two dimensions, action or what one does (active, passive) and sociability (prosocial, asocial), whether one approaches stressors alone or solicits the help of others. Direct action strategies are any behavior where the individual does something about the stressor, or moves toward the event, while indirect strategies are aimed at any behavior that separates the individual from the stressor. Prosocial strategies include any behavior that seeks out others to help the individual with the stressor, and asocial strategies include any efforts by the individual to resolve the stressor alone. It was this approach that formed the basis for the present study given the strong theory and empirical support behind the model, the lack of assumptions about whether certain types of coping are helpful or unhelpful, and the broader focus of the model (i.e., four strategies varying along two dimensions).

In this way, approaches to coping are neither dependent on nor restricted to emotions or objective strategies alone, or conflated with mental health/illness behaviors. Moreover, this approach allows for a given youth to endorse both asocial and indirect styles or prosocial and indirect styles and other combinations in their response to different types of stress events allowing for possible variability in coping behaviors. Because this model allows for youth coping to be placed along two overlapping continuum (resulting in scores anywhere in the four-square), it was hoped that the Dual Axis Model would provide a new, specific and nonsubjective illustration of what youth in foster care do when stress events occur and avoid the possible pitfalls of oversimplification (i.e., reduce coping to one approach only) and confounding coping response with maladjustment categories.

Beyond the theory of how the Dual Axis Model should work, several studies have demonstrated empirical support for the model. In a sample of military-dependent children living abroad who were facing closure of their community and imminent relocation, the hypothesized dimensional structure of the Dual Axis Model was strongly supported (Little, Lopez, \& Wanner, 2001). Further, the Dual Axis Model of coping strategy was linked to emotional adjustment in children (Lopez \& Little, 1996). These studies demonstrated that while the dimensions outlined in the Dual Axis Model may not be exhaustive, they do encompass a broad range of behavior, and that behavior is significantly associated with important mental health outcomes. More recently, Vanlede, Little, and Card (2006) tested the Dual Axis Model of coping in a sample of young adolescents transitioning from elementary to middle school, and again found it to be a useful paradigm. Specifically, the authors found that asocial coping consistently predicted negative changes in adjustment variables (greater depression, more aggression) in youth and that the coping scores were stable over time. Some preliminary evidence for the use of the Dual Axis Model with youth in foster care comes from Elzy, Clark, Dollard, and Hummer (2013), where approach and avoidance coping was examined in a sample of adolescent girls in group homes and residential facilities. The results indicated that the use of avoidant coping was related to less 
pathology in girls with the most trauma exposure, but use of approach coping was not related to trauma symptoms.

A final, important consideration related to the conceptualization and measurement of coping is the type of reporter. In their review of coping theory and measurement, Compas and colleagues (2001) found that self-report was the most common methodological approach in measurement of coping (Compas et al., 2001), and continues to be so (Rosenberg, Burt, Forehand, \& Paysnick, 2016), largely due to the rationale that self-report is likely a valid way to measure cognitive and behavioral responses that are not always unobservable by others.

\section{Coping over time}

Beyond documenting how and in what ways youth cope with events, research has also examined the stability of coping responses over time (Forns, Balluerka, Gómez-Benito, Kirchner, \& Amador, 2010).

Most of this research has demonstrated that types, such as approach or direct coping, tend to increase in use with age (Hampel \& Petermann, 2005), whereas types like avoidance are fairly invariable over time. Other authors have argued that one does not demonstrate a specific type of coping approach, but that, in general, as the number of exposures to trauma increase with age and time, youth tend to employ a greater variety of coping responses. That is, with time and opportunity, a youth's coping style is more likely to be a product of the demands in their environment, requiring the development of more skills (Seiffge-Krenke \& Klessinger, 2000). Youth in foster care represent a wide range of ages and surely a wider range of types of trauma exposures than typical youth. However, it is unclear if early life experience (i.e., child maltreatment, foster care) influence youth in foster care to become more likely to use one or more types of coping strategies and if these approaches remain stable, especially given that the child may be moved from one placement to another. Most research on coping stability in samples of typical youth or in clinical samples is mixed showing that coping style is not stable, while others demonstrate little change in coping style over time (Griffith, Dubow, \& Ippolito, 2000). The present study addressed this discrepancy by examining both cross-sectionally (i.e., dispositional) and over time (i.e., situational), the nature and consistency of coping styles in response to a range of significant trauma events in the lives of youth in foster care.

Because to-date there are no large-scale studies on the nature and stability of coping styles among youth in foster care, the predictions for the project were exploratory and for the most part, intended to be descriptive. Based on past research on non-foster youth however, it was predicted that youth in foster care would demonstrate a preferred or more frequently endorsed method for coping style and that this approach would be consistent over time, although no expectations about the type of coping preferred were made. It was also expected that the types of coping would vary within the sample and that the coping style reported by the youth would vary depending on the trauma event referenced. Given the wide age range of the sample, the analysis also examined coping style preferences relative to age of the youth. 


\section{Methods}

\section{Participants}

Participants included 542 (time 1), 377 (time 2), and 299 (time 3) youth placed in foster care currently living in the Midwest, and their caregivers. Forty-nine of the participants who did not have time 3 data were part of another study using the same study protocol designed to have only Time 1 and Time 2 data. There were no statistically significant differences in coping at Time 1, age, or gender between participants who participated in data collection at all three time points and those who did not complete data collection as intended. Because there were no baseline differences and because the purpose of the analyses were to describe the nature and trajectory of coping over time, all available data were used in the analyses. Specifically, the change over time analyses included all participants to provide estimates of the fixed effects over time. Seventy percent of the sample was retained from Time 1 to Time 2. The most common reason for loss-to-follow up across time was placement change (i.e., youth returning to biological caregivers or placed out of the regional catchment area). Twenty-nine youth were lost to attrition for this same reason from Time 2 to Time 3 . About half of the sample resided in residential facilities (53\%) while the remaining youth lived in traditional foster home settings. The youth ranged in age from 8 to 22 years $(M=13.28$ years, $S D=3.04)$.

The sample consisted of 291 males and 251 females, with 54\% of the sample selfidentifying as African American, 24\% as European American, 12\% as Multiracial, and 5\% as Hispanic. According to state social service records, youth in the study had spent an average of 4.23 years ( $\mathrm{SD}=2.67$ years $)$ in foster care. On average, the youth participants had 9.15 distinct placements ( $\mathrm{SD}=6.57$ placements) by the time of the first wave of data collection. Youth with a prior diagnosis of mental retardation or autism were excluded from the study due to the reliance on youth self-report for data collection. All youth were participants in the SPARK Project (Studying Pathways to Adjustment and Resilience in Kids), a federally funded longitudinal research study designed to investigate pathways between maltreatment exposure and foster placement and emotional, behavioral, physical, and academic outcomes.

Maltreatment history-Maltreatment experienced across the course of youth's lives was obtained via youth report. Given that the study questions addressed coping and not amount and degree of maltreatment, only descriptive information on the sample's maltreatment history is included. The questions about abuse events experienced were derived from the MMCS (English, 1997). The MMCS is a commonly-used measure of abuse types and severities that has demonstrated measurement fidelity of the maltreatment construct (English et al., 2005). Items from the MMCS were reworded to facilitate self-report (e.g., the item "the child was hit or kicked in the face" was changed to "Have you ever been hit or kicked in the face?"). Youth were asked about four types of maltreatment: physical abuse, sexual abuse, psychological abuse, and neglect, and the frequency with which each endorsed event occurred. If a child responded affirmatively to whether or not a certain abuse event had ever occurred, s/he received a follow-up question asking how often that abuse event had happened. The physical abuse subscale of the MMCS included 19 items measuring a range 
of physical abuse events (e.g., "how often did someone kick or punch you?"). The sexual abuse subscale consisted of 12 items measuring types of sexual abuse experienced during the course of the child's life (e.g., "Has anyone ever forced you to look at their sexual parts?"). The psychological abuse subscale had 26 items addressing psychological maltreatment by someone in the child's life (e.g., "how often has anyone ever blamed you for their own problems?"). Finally, the neglect subscale had 25 items about lifetime experience of neglect by the child's caregivers (e.g., "Did your parents make sure you saw a doctor if you needed one?"). Most youth in the study reported experiencing multiple types of maltreatment (e.g., neglect and physical abuse). Total endorsed events averaged 15.32 ( $\mathrm{SD}=11.02)$ across all time points with $20 \%$ endorsing 24 or more maltreatment events. At Time 1, youth were asked to report abuse occurring "In their lifetime" and at Time 2 and Time 3, "Since your last visit" (or in the last 3 months).

Neglect: Youth endorsed $2.88(\mathrm{SD}=4.14)$ neglect events on average across all time points with a range of 0 to 22 events. Sixty-eight percent of the sample endorsed at least 1 neglect event ever at Time 1 with $10 \%$ endorsing more than 8 . At Time 2, 77\% endorsed at least 1 event and at Time 3,77\% endorsed at least 1 event.

Physical Abuse: Youth endorsed $4.21(\mathrm{SD}=3.30)$ physical abuse events on average across all time points with a range of 0 to 16 events. Eighty-eight percent of the sample endorsed at least 1 physical abuse event ever at Time 1 with $10 \%$ endorsing more than 8 events. At Time $2,39 \%$ endorsed at least 1 event and at time 3,28\% endorsed at least 1 event.

Psychological Abuse: Youth endorsed $6.55(\mathrm{SD}=5.00)$ psychological events on average across all time points with a range of 0 to 23 events. Ninety-one percent of the sample endorsed at least 1 psychological abuse event ever at Time 1 with $10 \%$ endorsing more than 12 events. At Time 2, 58\% endorsed at least 1 event and at time 3,43\% endorsed at least 1 event.

Sexual Abuse: Youth endorsed 1.68 ( $\mathrm{SD}=2.72)$ sexual abuse events on average across all time points with a range of 0 to 12 . Forty-five percent of the sample endorsed at least 1 sexual abuse event ever at Time 1 with 10\% endorsing more than 5 events. At Time 2,16\% endorsed at least 1 event and at time 3,9\% endorsed at least 1 event.

\section{Procedures}

Consent was obtained from the state social service agency. The study was approved by the university Institutional Review Board and the State's Department of Social Services Review Board. Youth and caregivers were informed about the study, the voluntary nature of participation, and limits to confidentiality before they provided consent and assent. Although caregivers participated in the larger SPARK study, for the present study, only data from the youth was included.

Youth provided data on both maltreatment history and coping at three time points spaced three months apart, making the time from the first report or Time 1 to Time 3, six months apart. Given that youth in foster care tend to change homes and move frequently, the time frame was chosen to allow time for change to occur in the developmental constructs of 
interest while also promoting the likelihood that most youth in the project would be able to provide data at all three time points. All survey items were answered using an audiocomputer assisted self-interview program (A-CASI) on a laptop computer. The A-CASI provided participants with greater autonomy and confidentiality in answering survey questions, and allowed those who needed reading support to better comprehend the questionnaires. Graduate research assistants in clinical child psychology debriefed participants after survey administration to assess for and manage mood changes, suicidal ideation, and current abuse. Children and caregivers were compensated for their time and participation with gift cards. See XXX, XXX, XXX, and XXX (2012), for further details on methodology including recruitment strategy, informed consent, data collection procedures, and maintenance of participant confidentiality and safety.

\section{Measures}

Coping-Coping was measured using the Behavioral Inventory of Strategic Control (BISC; Little, Lopez, \& Wanner, 2001; Lopez \& Little, 1996). This measure was developed from an action-theory perspective, and is based on the idea that children's coping strategies vary along four dimensions of strategic behavioral control: Direct Action, Indirect Action, Prosocial Action, and Asocial Action. Simply put, this instrument measures whether children report moving towards or away from a problem, and whether they enlist or avoid support from others. The BISC assesses coping strategy used in different potentially stressful situations or frames in a child's life. For example, the BISC asks "When I have problems keeping a good friend..." and the child can select a direct action behavior ("I try to work it out"), an indirect action behavior ("I do something else instead), a prosocial behavior ("I seek out others") and an asocial behavior ("I think others just get in my way."). The measure includes five frames in total including stressors related to social problems, academic problems, general stressors, and additional frames were added specific to foster care including problems relating to changing homes and getting along with foster family members. The BISC has demonstrated adequate reliability and validity, and low-to-moderate stability (Little, Lopez, \& Wanner, 2001; Lopez \& Little, 1996; Vanlede, Little, \& Card, 2006). The longitudinal timeframe of the current study is consistent with previous literature, which validated the use of the BISC with youth across three time points over the span of four months; findings suggested that the fundamental structure of the coping dimensions were nearly identical at each time point (Little et al., 2001). Construct validity was demonstrated through confirmatory factor analyses supporting the hypothesized structure of the Dual Axis Model of Coping (Little et al., 2001; Vanlede et al., 2006).

Youth self-report of coping is the most common method of assessing coping behaviors (Compas et al., 2001, Seiffge \& Krenke, 2011) and previous research has shown that correlations between youth and parent report are often small and statistically insignificant (Ptacek, Pierce, \& Thompson, 2006) thereby suggesting that youth self-report of coping responses is an appropriate method for assessment. On the BISC, participants responded to three questions (e.g., for direct action type; I work it out, I figure it out, I try to solve it) for each of the five frames and indicated their use of each of the coping behaviors on a fourpoint Likert scale. The 9 item alphas from the original scale as intended range from .83 for 
Change Direct to .91 for Academic Asocial. The alphas for the summary variables of Direct, Indirect, Prosocial, and Asocial in the present study were $.90, .92, .93$, and .95 respectively.

Initially, data reduction techniques were employed to handle the redundancy in the BISC items. The three items with the same frame, scale, and stem with possible scores ranging from 1 to 5 were summed. For example responses to the Direct Action scale questions "When I have problems making new friends ... I try to work it out, I try to figure it out, and I try to solve it" were summed. Means were then obtained across stems within a frame at each time point. For example, the previously mentioned sums for "When I have problems making new friends, When I have problems getting a friend to do something together with me, and When I have problems keeping a good friend" were averaged together to create a mean for the Social frame. Similar reduction was done for each frame and scale at each time point. This yielded variables for each of the four scales (Direct Action, Indirect Action, Prosocial Behavior, and Asocial Behavior) for each of the five frames (Social, Academic, General, Change, and Family) at each of the three time points or 60 total variables to be analyzed. Each of these summed variables ranged from 3 to 15 with standard deviations around 2.5 .

\section{Results}

\section{Most commonly endorsed or preferred coping style by person}

To determine if foster youth had a preferred coping style, the four means for each coping type were compared to each other within a participant. A mean difference of .50 was used as indicative of a preference, as a difference of .50 represents a standardized effect size of .25 for the difference between two within-person scores. At Time 1, 377 participants preferred a single coping style using this definition, as can be seen in Table 1. Most of these participants, $58.5 \%$ of the total sample at Time 1, preferred direct coping strategies. For some participants, multiple coping styles were preferred. For example, 26 participants at Time 1 had means for direct, indirect, and prosocial that were more than .50 points higher than the mean for Asocial but closer than .50 points to each other as can be seen in row 5 . Direct coping was the preferred style for more than $50 \%$ of the sample at each time point. About $7 \%$ of the sample showed no preference for a style at Time 1. The number of people showing no coping preference increased to about 13\% at Times 2 and 3. Forty-nine percent (185/376) of the participants had the same preferred coping style at Times 1 and 2 with 158 preferring direct coping. Fifty-four percent of the participants (148/272) had the same preferred coping style at Times 2 and 3.

\section{Stability of coping over time}

To determine if the coping scores were stable over time, SAS PROC MIXED with Maximum Likelihood estimation was used to examine the effect of time with repeated observations nested within persons. For each of the four coping types, there were no significant differences over time (Direct Action, $F(2,673)=.36, p=.70$; Indirect Action, $F(2,673)=.93, p=.40 ;$ Prosocial Action, $F(2,673)=.41, p=.66$; Asocial Action, $F(2,673)$ $=.33, p=.72$ ). Mean scores and standard deviations at each time point for each of the four coping types are presented in Table 2. Figure 1 presents the mean scores for each of the four 
coping types at each time point by gender. Asocial coping tended to have the lowest mean for both males and females at all three time points. Additionally, males' mean scores for Direct Action tended to increase at each subsequent time point, whereas females endorsed similar levels of Direct Action over time. Overall, coping means were quite similar for males and females at all three time points.

Given the wide age range of the sample, differences in coping response by age were examined. Using time 1 data only, the results indicated that there were no significant differences in having a single coping preference by age category, $\mathrm{X}^{2}=3.74, p=.15$. Seventy-one percent of participants aged 11 and younger, $65 \%$ of 12 to 14 year-old participants, and $76 \%$ of participants 15 and older indicated one preferred coping strategy (direct coping). To examine this pattern over time, means and standard deviations were examined across different age groups (e.g., under 12 years old, 12-15 years old, 15+ years old) for each coping type at each time point. Overall, the youngest $(<12)$ group tended to have higher means for Direct Action at every time point $[M=11.0$ (2.22), 11.24 (2.38), 11.10 (2.39), respectively], in comparison to the $12-15$ [ $M=10.88(1.88), 10.63(2.01)$, 10.87 (2.03), respectively] and 15+ group [ $M=10.81$ (2.08), 10.90 (1.95), 11.08 (2.06), respectively]. Additionally, the youngest group had the lowest overall mean scores for Asocial Coping at each time point, [ $M=7.32$ (2.71), 6.84 (2.69), 6.91 (2.70), respectively], in comparison to the 12-15 [ $M=7.41$ (2.28), 7.54(2.23), 7.57 (2.39), respectively] and 15+ group $[M=7.58$ (2.23), 7.70 (2.22), 7.66 (2.05), respectively]. The results suggest that the youngest group was much more likely to endorse a Direct Action coping style and least likely to endorse an Asocial Behavior across every time point than the older youth sampled.

To gain a better understanding of the nature of change in coping across time, change scores were examined between time points using descriptive statistics. Table 3 shows the percentage of the sample who increased or decreased by more than 1 point between successive time points. Recall Table 1 reporting the means and standard deviation of each coping type at each time point. A change of 1 point represents a change of $.4-.48$ of a standard deviation. Although the overall group mean was stable between times 1 and 2, about half of the children's scores changed on each coping type between subsequent time points. For example, 28\% increased their Direct Action score and 22\% decreased their Direct Action score by at least 1 point or more between time point 1 and 2. Results indicated that a large percentage of children endorsed higher or lower scores for each coping type in comparison to the previous time point, which suggests that the degree of coping endorsed did not remain the same across time. For each change in time point from Time 1 to Time 2 or from Time 2 to Time 3, the percent of youth who increased in scores and the percent of youth who decreased in scores were similar allowing for the overall group mean to remain stable, despite within-person changes in scores.

In addition, the percentage of the sample who increased or decreased by more than 1 point between successive time points for each coping type by gender was examined. Overall, the patterns of changes are quite similar for males and females. More males tended to decrease in their use of Indirect Action by more than 1 point between Time 1 and Time 2 and between Time 2 and Time 3 than females in the sample. 
The data were also examined to determine if there was a pattern of coping style that varied based on type of maltreatment exposure. To help illustrate the relations, two groups were created: a) the Any group or those who endorsed one event of any type of maltreatment, and b) the High group or those that endorsed high levels of maltreatment, that is, 7 or more events of a given type of maltreatment (or the top 10\%).

For those who experienced Any Neglect (i.e., endorsed at least 1 neglect event, $\mathrm{n}=249$ ) 84\% endorsed a Direct Action coping style, 8\% endorsed Indirect Action, 3\% endorsed Prosocial, and 5\% endorsed Asocial. Seventy-seven percent of the High Neglect group ( $\mathrm{n}=$ 52) endorsed Direct Action, whereas $12 \%$ endorsed Indirect, $4 \%$ endorsed Prosocial, and $8 \%$ endorsed Asocial.

With regards to participants who reported Any Physical abuse ( $\mathrm{n}=329), 84 \%$ of the sample endorsed Direct Action, 8\% endorsed Indirect, 3\% endorsed Prosocial, and 5\% endorsed Asocial. Additionally, for those who classified as High Physical abuse $(\mathrm{n}=71) 89 \%$ endorsed Direct Action, 7\% endorsed Indirect, 1\% endorsed Prosocial, and 3\% endorsed Asocial.

Next, for participants with Any Psychological abuse $(n=341) 84 \%$ of youth endorsed Direct Action, $8 \%$ endorsed Indirect, 3\% endorsed Prosocial, and 5\% endorsed Asocial coping. For those who experienced High Psychological abuse $(\mathrm{n}=169)$, 85\% endorsed Direct coping, $7 \%$ endorsed Indirect coping, 3\% endorsed Prosocial, and 5\% endorsed Asocial coping. For youth who experienced Any Sexual abuse $(\mathrm{n}=162), 84 \%$ endorsed Direct, $9 \%$ endorsed Indirect, $3 \%$ endorsed Prosocial, and 4\% endorsed Asocial. Finally, for youth with High Sexual abuse ( $\mathrm{n}=33$ ), $88 \%$ of youth endorsed Direct coping, 3\% endorsed Indirect, 3\% endorsed Prosocial, and 6\% endorsed Asocial coping. Results suggest that when participants endorse only a single coping preference, they are significantly more likely to endorse Direct Action coping than all the other coping types, regardless of whether the participant experienced Any Maltreatment type or High Maltreatment.

\section{Coping responses by stress event}

To determine if there were significant differences in coping scores based on type of nonmaltreatment-related event or Frame (i.e., general, social, academic stressors, problems relating to changing homes and getting along with foster family members), similar repeated measures analyses were conducted using SAS PROC mixed. Each participant response was characterized by type of event Frame with 5 levels, coping type with 4 levels, and time with 3 levels. There were significant main effects for situation or Frame $F(4,2166)=14.62, p<$. 0001 and Type of coping $F(3,1626)=2938.59, p<.0001$, but not a significant main effect for Time $F(2,673)=.67, p=.51$. Pairwise tests of the differences in the least squares means indicated that the means for the changing foster homes and getting along with foster family members were significantly lower than means for coping with Academic, General, and Social events. The coping type means were all significantly different from one another with Direct (10.91) being the highest followed by Prosocial (8.74), Indirect (8.13), and Asocial (7.36). A significant Frame by type of coping interaction, $F(12,6492)=15.32, p<.001$ was found with direct coping relatively high for academic stressors and low for changing foster home stressors. 


\section{Discussion}

The purpose of the present study was to provide first-time evidence of the nature and consistency of coping behavior over time reported by youth in foster care. Results suggest that youth in foster care differ in the kinds of coping behaviors they report, that the coping style they use depends on the kind of event they are coping with, and that their coping styles are somewhat consistent across a time span of about six months.

Regarding preferred coping style, most of the sample indicated the direct style was their most commonly employed way of approaching a problem or conflict in their lives. This "going toward the problem" style or "doing something about it" was a stable approach across time points. Consistent with other research on youth (e.g., Tsao, Fanurik, \& Zeltzer, 2003), doing something about a problem or approaching the conflict is a commonly endorsed strategy, especially for school-age youth. While in most situations, moving towards a problem may be an effective strategy, the effectiveness of the direct coping approaches used by youth in foster care has yet to be tested. It may be useful for practitioners working with foster youth to consider when a youth's direct coping or "approaching the problem" tendency is helpful or harmful, and to help youth vary their coping style accordingly (e.g., a practitioner might help a youth practice using a prosocial strategy to elicit help from a teacher rather than their usual direct strategy of confronting when a peer poses a threat; a practitioner might validate and reinforce use of a direct strategy of talking to a teacher about why the youth is failing a class). Although there were no age-specific effects for different types of coping endorsed by the youth, the average length of time in care for the sample was four years, suggesting that for youth in care for a significant portion of their lives, direct approaches to problems is likely to be a consistent pattern no matter the chronological age of the child. No gender differences in coping were found. A few studies of coping over time have found results similar to the present study specifically that approaches to coping are fairly consistent over time for both males and females (Kirchner et al., 2010).

The use of asocial and indirect coping styles was equally endorsed by the sample, meaning neither approach was more common than the other, and both were less common than endorsements of direct coping. Importantly, prior literature suggests youth exposed to trauma tend to commonly endorse emotion-focused or avoidant coping (similar to indirect coping in the present study), rather than direct coping, as found in the present study (Khamis, 2015; Fortier et al., 2009). Current findings may differ from extant literature on foster youth and youth exposed to trauma due to the larger sample size of the present study and examination of coping at multiple time points. Further, participants in the current sample may represent a more heterogeneous sample of youth, who may have been exposed to various types and severities of maltreatment and other stressors, thus resulting in coping responses that differ from previous findings.

It is also important to note that a sizeable portion of the sample endorsed using more than one coping style. The use of multiple styles with varying combinations was also common suggesting that a portion of youth in foster care may have some flexibility in how they approach problems. Although it is not known if being flexible or having a range of responses is related to positive behavior in youth, perhaps findings like this one lessen the need to 
consistently test to see if specific kinds of coping are associated with a given kind of (mal)adjustment. Researchers may do well to examine how different combinations of approaches are related to outcomes for youth well-being. In contrast, the results also indicated that $7 \%$ of the sample reported no preferred coping style and that over time, the endorsement of no preference almost doubled, increasing to $13 \%$ of the sample by time three. Having no preferred style could indicate some risk for pathology, in that not having a common approach or set of common approaches could mean the youth may be slow to respond to a problem or conflict as the youth may have to consider, perhaps for a longer period of time than someone who shows a strong preference, just which strategy is the one to use in a given situation. Conversely, it is also possible that having no preferred style suggests that some youth may be less impulsive and thoughtful about how they respond to a dilemma. Future research is needed however, to determine if "no preferred style" is a consistent kind of coping and whether either possible explanation for the pros or cons of this result has merit.

Regarding stability of coping style over time, the results suggested significant differences for the degree of endorsement of each type of coping across time and across the sample.

Although the overall means on each type of coping appear to be stable for the overall sample and were not significantly different over time, many youth changed their scores on the respective type of coping over time. In fact almost equal numbers of youth increased and decreased in their scores on a given type of coping over time. This pattern was not unique to any particular type of coping, although the greatest change was found for direct coping. Identifying that endorsements of coping are stable over time, but that they also change in degree and magnitude across coping types, is a new finding for the field and suggests that coping styles among foster youth are not homogenous. To determine if the patterns identified in the coping styles of youth in foster care are related to the kind of event prompting the coping behavior, the analyses also revealed some new findings. Namely, across all of the frames or situations, including social, academic, general, and the fosterspecific situations, direct coping had the highest endorsement, followed by prosocial, indirect, and asocial types of coping responses. Overall, the results suggest that no matter the type of event, youth in foster care are more likely to report directly responding to the event, followed by asking others to help.

Although pathology related to these patterns was not investigated, it seems reasonable to surmise that using the same kind of approach (i.e., direct), above and beyond other approaches, no matter what the nature of the problems might be, could impair a youth's ability to flexibly address different stressors. Youth in foster care who use the direct approach overwhelmingly across all types of events may find this strategy ineffective when so many events may indeed be outside of their control (Nybell, 2013). Moreover, if youth do not have others who provide help or who can alter the course of events, yet they consistently ask others for help no matter the problem, this may lead to difficulty (Augsberger, 2014). Although the present study did not directly test this notion, prior research has provided some support suggesting that the type of stressor may influence how adaptive or maladaptive a given type of coping may be for various situations (Tolan, Guerra, \& Montaini-Klovdahl, 2002). Thus, it may be beneficial for practitioners to work with youth on matching various coping styles to different situations, making the youth more adaptable. 
The present study provides first-time evidence of the nature and stability of coping styles endorsed by youth in foster care. Using a large sample of youth, the findings suggest that for youth in foster care, how one copes is not straightforward. Although some of the patterns suggest that direct coping is most common, youth in foster care also endorsed other types of coping, implicating the necessity of conceptualizing coping in any other sample as a multifactored variable. There is little doubt that youth in foster care are exposed to more nonnormative trauma events than typical youth, and as such, how they develop their response systems to problems is an issue of utmost importance for the field. Given that for some youth, foster care is not a particularly temporary experience, the results of the present study could assist caregivers and social service workers in their efforts to better understand the trajectory and functioning of youth in foster care over time, and may contribute to practice and policy changes. These results provide a foundation upon which future research may build, ultimately linking predictors, such as placement changes, to particular patterns and trajectories of coping, and then, those patterns and trajectories to mental health functioning. The findings are the first piece of the process in improving outcomes in foster youth, a goal shared by researchers, practitioners, child welfare administrators, and policy makers.

\section{Limitations}

Although the results of the present study are important, they are not without limitations. First, the sample included youth exposed to maltreatment, but was specific to those in foster care making the findings likely limited to only other youth in state custody or foster care. Second, although the sample had a documented history of abuse, the nature of this exposure was not included as a predictor in the present study. Future research is needed to determine if aspects of abuse (i.e., type differences, severity of exposure, and frequency of exposure) are active variables in the maltreatment-coping-adjustment relation. Third, the present study included a measurement of coping style that was not necessarily inclusive of other tools used in past research, which could make the results hard to consolidate with previous findings. It is possible, however, that the BISC, which provides information simply on how youth move toward or away from problems, seek others or not for assistance, could serve as the foundation for understanding more nuanced types of coping like emotion/problem focused coping where the coping behavior is really more descriptive of the approach one takes toward an event (i.e., focused on how I felt) and not if one seeks help or tends to ignore problems as they arise. Fourth, it is possible that the stability of coping strategies may have been influenced by other factors, such as engagement in coping-focused therapeutic interventions. It is not clear from the present study how many youth were engaged in treatment or specifically, cognitive-based approaches to treatment, which could have influenced the types of coping endorsed and possibly the results of the study. Finally, as is the case with most studies on youth in foster care, some portion of the youth were unable to complete all three time points (49 youth were not asked to complete time 3 as they completed the same study protocol, but were added to the present study at a later time) due to placement changes. Although there were no significant differences on demographic or study variables between those that completed all three time points and those that did not, it is possible that the loss of $30 \%$ of the participants from Time 1 to Time 2 dampens somewhat the robustness of the findings. 


\section{Directions for future research}

The current findings advance the field by identifying the complexity and multidimensionality of coping styles for youth in foster care, yet a number of questions require future investigation. The results provide some support for the theoretical approach advocated by Lazarus and Folkman (1984), and later Hobfoll et al. (1994) in their extension via the Dual Axis Model of Coping. Although youth in foster care appear to endorse a direct style approach to problems, this approach is not universal as the data is clear that the combinations of direct, indirect, prosocial, and asocial also occur and that some styles of coping can be specific to the type of problem, even problems specific to the foster care experience. Although the findings provide support for preferred coping styles for youth in foster care, it remains unclear how these coping preferences are related to mental health outcomes. It is also possible some coping styles are incongruous (i.e., direct action) for coping with events that are outside of the youth's control.

Current findings suggest that youth in foster care may employ high levels of direct coping strategies, differing from previous findings which suggests foster youth are more likely to employ avoidant strategies (Elzy et al., 2013). Preferred coping styles can be influenced by a number of factors, such as the present situation, previous learning history, or degree of maltreatment experienced. Additionally, stability of coping responses may also be influenced by coping-focused therapeutic interventions for youth in foster care. Future research should consider assessment of current therapeutic involvement of youth in foster care to assess for coping style changes related to intervention skill building. Further, the field would benefit from research assessing how maltreatment history (i.e., frequency or severity of maltreatment events) may be contributing to youth coping styles.

Coping types are likely dependent in some part on the demands of the problem at hand. The present study included some attention to how different situations may or may not elicit different coping style endorsements from the youth participants, but the field would benefit from more investigations of how the developmental process of coping can be impacted by the child's environment. For youth in foster care, the exposure to maltreatment, while cognitive abilities are in-flux, could play a role in the type and stability of the development of coping behaviors. As cognitive skills become more sophisticated over time (Compas et al., 2001) so too might the child's understanding of their coping options. The present study did not consider age of onset of abuse or other trauma events, and it will be important for future studies to investigate how maltreatment or foster care placement during different developmental time periods may influence the expected developmental trajectory of coping behavior.

\section{Acknowledgments}

This research was supported by funding from the National Institutes of Mental Health, RO1 Grant MH079252-03 as well as funding from the National Institute on Drug Abuse, F31 grant DA034423 awarded to Joy Gabrielli. The writing of this manuscript was supported in part by Joy Gabrielli's participation in the NIDA T32 fellowship training grant DA037202. 


\section{References}

Augsberger A. Strategies for engaging foster care youth in permanency planning family team conferences. Children and Youth Services Review. 2014; 43:51-57. DOI: 10.1016/j.childyouth. 2014.04.015

Browne D. Coping alone: Examining the prospects of adolescent victims of child abuse placed in foster care. Journal of Youth and Adolescence. 2002; 31(1):57-66. DOI: 10.1023/A:1014037100581

Carlo G, Mestre MV, McGinley MM, Samper P, Tur A, Sandman D. The interplay of emotional instability, empathy, and coping on prosocial and aggressive behaviors. Personality and Individual Differences. 2012; 53(5):675-680. DOI: 10.1016/j.paid.2012.05.022

Compas BE, Connor-Smith JK, Saltzman H, Harding Thomsen A, Wadsworth ME. Coping with stress during childhood and adolescence: Problems, progress, and potential in theory and research. Psychological Bulletin. 2001; 127(1):87-127. DOI: 10.1037//0033-2909.127.1.87 [PubMed: 11271757]

Connor-Smith J, Compas BE, Wadsworth ME, Thomsen AH, Saltzman H. Responses to stress in adolescence: Measurement of coping and involuntary stress responses. Journal of Consulting and Clinical Psychology. 2000; 68(6):976-992. DOI: 10.1037/0022-006X.68.6.976 [PubMed: 11142550]

Elzy M, Clark C, Dollard N, Hummer V. Adolescent girls' use of avoidant and approach coping as moderators between trauma exposure and trauma symptoms. Journal of Family Violence. 2013; 28(8):763-770. DOI: 10.1007/s10896-013-9546-5

English, DJ. the LONGSCAN Investigators. Modified Maltreatment Classification System (MMCS). 1997. Retrieved from http://www.unc.edu/depts/sph/longscan/pages/maltx/mmcs/LONGSCAN $\% 20 \mathrm{MMCS} \%$ Coding.pdf

English DJ, Upadhyaya MP, Litrownik AJ, Marshall JM, Runyan DK, Graham JC, Dubowitz H. Maltreatment's wake: The relationship of maltreatment dimensions to child outcomes. Child Abuse \& Neglect. 2005; 29:597-619. DOI: 10.1016/j.chiabu.2004.12.008 [PubMed: 15970327]

Forns M, Balluerka N, Gómez-Benito J, Kirchner T, Amador JA. Multilevel approach to stressors, coping and psychopathological symptoms 1, 2. Psychological reports. 2010; 106(1):262-278. DOI: 10.2466/PR0.106.1.262-278 [PubMed: 20402453]

Fortier MA, DiLillo D, Messman-Moore TL, Peugh J, DeNardi KA, Gaffey KJ. Severity of child sexual abuse and revictimization: The mediating role of coping and trauma symptoms. Psychology of Women Quarterly. 2009; 33(3):308-320. DOI: 10.1111/j.1471-6402.2009.01503.x

Gil KM, Wilson JJ, Edens JL. The stability of pain coping strategies in young children, adolescents, and adults with sickle cell disease over an 18-month period. The Clinical Journal of Pain. 1997; 13(2):110-115. Retrieved from http://search.proquest.com/docview/619080602?accountid=14556. [PubMed: 9186018]

Greer TM. Coping strategies as moderators of the relation between individual race related stress and mental health symptoms for African American women. Psychology of Women Quarterly. 2011; 35(2):215-226. DOI: 10.1177/0361684311399388

Griffith MA, Dubow EF, Ippolito MF. Developmental and cross-situational differences in adolescents' coping strategies. Journal of Youth and Adolescence. 2000; 29(2):183-204. DOI: 10.1023/A: 1005104632102

Hager AD, Runtz MG. Physical and psychological maltreatment in childhood and later health problems in women: An exploratory investigation of the roles of perceived stress and coping strategies. Child Abuse \& Neglect. 2012; 36:393-403. DOI: 10.1016/j.chiabu.2012.02.002 [PubMed: 22609072]

Halstead M, Johnson SB, Cunningham W. Measuring coping in adolescents: An application of the ways of coping checklist. Journal of Clinical Child Psychology. 1993; 22(3):337-344. Retrieved from http://search.proquest.com/docview/618423950?accountid=14556.

Hampel P, Petermann F. Age and gender effects on coping in children and adolescents. Journal of Youth and Adolescence. 2005; 34(2):73-83. doi:http://dx.doi.org/10.1007/s10964-005-3207-9. 
Hobfoll SE, Dunahoo CL, Ben-Porath Y, Monnier J. Gender and coping: The dual-axis model of coping. American Journal of Community Psychology. 1994; 22(1):49-82. Retrieved from http:// search.proquest.com/docview/618589054?accountid=14556. [PubMed: 7942644]

Khamis V. Coping with war trauma and psychological distress among school-aged Palestinian children. American Journal of Orthopsychiatry. 2015; 85(1):72-79. DOI: 10.1037/ort0000039 [PubMed: 25642655]

Kirchner T, Forns M, Amador JA, Muñoz D. Stability and consistency of coping in adolescence: A longitudinal study. Psicothema. 2010; 22(3):382-388. Retrieved from http://search.proquest.com/ docview/754054249?accountid=14556. [PubMed: 20667264]

Krattenmacher T, Kühne F, Führer D, Beierlein V, Brähler E, Resch F, Möller B. Coping skills and mental health status in adolescents when a parent has cancer: A multicenter and multi-perspective study. Journal of Psychosomatic Research. 2013; 74(3):252-259. DOI: 10.1016/j.jpsychores. 2012.10.003 [PubMed: 23438718]

Lazarus, RS., Folkman, S. Stress, appraisal, and coping. New York: Springer; 1984.

Little TD, Lopez DF, Wanner B. Children's action-control behaviors (coping): A longitudinal validation of the behavioral inventory of strategic control. Anxiety, Stress and Coping. 2001; 14(3):315-336. DOI: 10.1080/10615800108248360

Lopez DF, Little TD. Children's action-control beliefs and emotion regulation in the social domain. Developmental Psychology. 1996; 32(2):299-312.

Moos RH, Holahan CJ, Beutler LE. Dispositional and contextual perspectives on coping: Introduction to the special issue. Journal of Clinical Psychology. 2003; 59(12):1257-1259. DOI: $10.1002 /$ jclp. 10218 [PubMed: 14618595]

Nybell LM. Locating “youth voice:" considering the contexts of speaking in foster care. Children and Youth Services Review. 2013; 35(8):1227-1235. DOI: 10.1016/j.childyouth.2013.04.009

Persike M, Seiffge-Krenke I. Competence in coping with stress in adolescents from three regions of the world. Journal of Youth and Adolescence. 2012; 41(7):863-879. doi: http:// dx.doi.org.www2.lib.ku.edu/10.1007/s10964-011-9719-6. [PubMed: 21983844]

Ptacek JT, Pierce GR, Thompson EL. Finding evidence of dispositional coping. Journal of Research in Personality. 2006; 40(6):1137-1151. Retrieved from http://search.proquest.com.www2.lib.ku.edu/ docview/621518060? accountid=14556.

Sesar K, Šimić N, Barišić M. Multi-type childhood abuse, Strategies of coping, and psychological adaptations in young adults. Croatian Medical Journal. 2010; 51:406-16. DOI: 10.3325/cmj. 2010.51.406 [PubMed: 20960590]

Santiago CD, Wadsworth ME. Coping with family conflict: What's helpful and what's not for lowincome adolescents. Journal of Child and Family Studies. 2009; 18(2):192-202.

Seiffge-Krenke I. Coping with relationship stressors: A decade review. Journal of Research on Adolescence. 2011; 21(1):196-210. Retrieved from http://search.proquest.com.www2.lib.ku.edu/ docview/863419850?accountid=14556.

Seiffge-Krenke I, Klessinger N. Long-term effects of avoidant coping on adolescents' depressive symptoms. Journal of Youth and Adolescence. 2000; 29(6):617-630. Retrieved from http:// search.proquest.com/docview/619533103?accountid=14556.

Tolan, PH., Guerra, NG., Montaini-Klovdahl, L. Handbook of children's coping: Linking theory and intervention. Plenum Press; New York, NY: 1997. Staying out of harm's way: Coping and the development of inner-city children; p. 453-479.Retrieved from http://search.proquest.com/ docview/619154081? accountid=14556

Tsao JCI, Fanurik D, Zeltzer LK. Long-term effects of a brief distraction intervention on children's laboratory pain reactivity. Behavior Modification. 2003; 27(2):217-232. DOI: 10.1177/0145445503251583 [PubMed: 12705106]

Vanlede M, Little TD, Card NA. Action-control beliefs and behaviors as predictors of change in adjustment across the transition to middle school. Anxiety, Stress \& Coping: An International Journal. 2006; 19(2):111-127. DOI: 10.1080/10615800600632896 


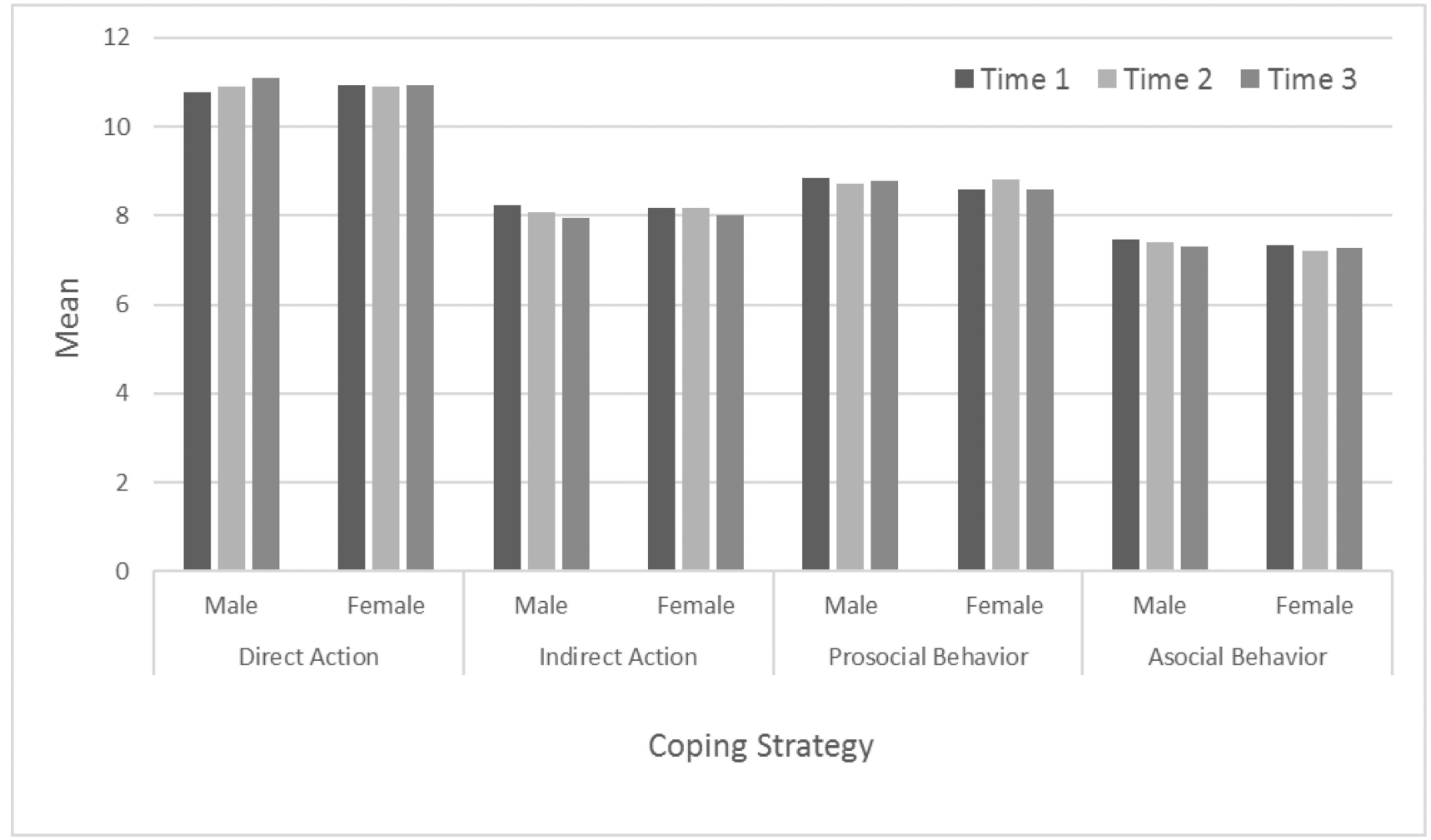

Figure 1.

Means on the BISC at Each Time Point by Gender 


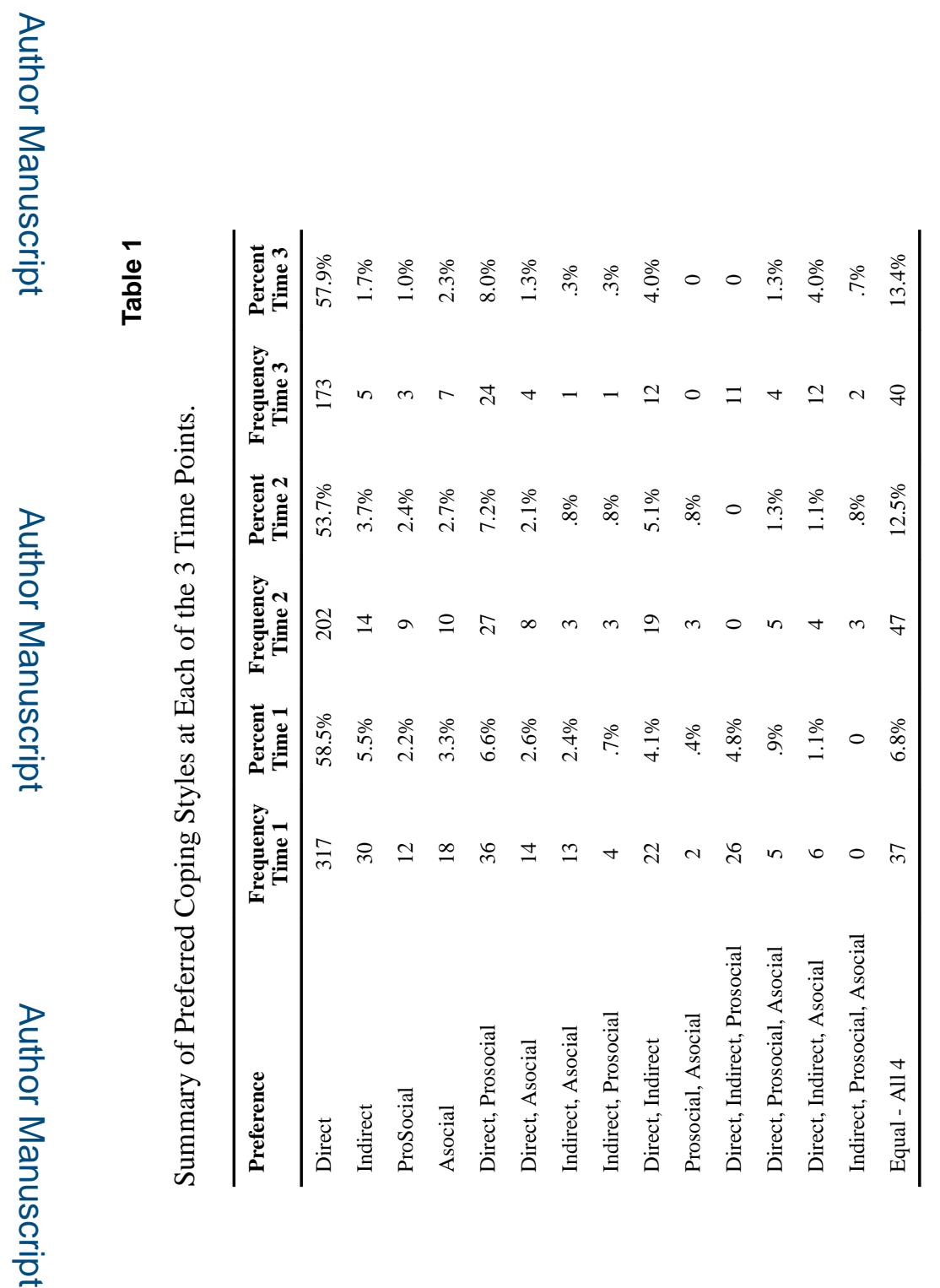

Child Abuse Negl. Author manuscript; available in PMC 2018 August 01. 
Table 2

Means and Standard Deviations on the BISC at each time point.

\begin{tabular}{|l|l|l|l|l|}
\hline & $\begin{array}{l}\text { Direct } \\
\text { Action }\end{array}$ & $\begin{array}{l}\text { Indirect } \\
\text { Action }\end{array}$ & $\begin{array}{l}\text { Prosocial } \\
\text { Behavior }\end{array}$ & $\begin{array}{l}\text { Asocial } \\
\text { Behavior }\end{array}$ \\
\hline Time 1 $(\mathrm{N}=542)$ & $10.85(2.08)$ & $8.20(2.14)$ & $8.74(2.13)$ & $7.42(2.43)$ \\
\hline Time 2 $(\mathrm{N}=377)$ & $10.90(2.17)$ & $8.12(2.30)$ & $8.77(2.28)$ & $7.32(2.44)$ \\
\hline Time 3 $(\mathrm{N}=299)$ & $11.01(2.20)$ & $7.98(2.31)$ & $8.68(2.22)$ & $7.29(2.48)$ \\
\hline
\end{tabular}


Table 3

Percentage whose preference changed by more than 1 point between successive time points.

\begin{tabular}{|l|l|c|c|}
\hline & Change & Increase More than 1 & Decrease More than 1 \\
\hline Direct Action & Time 1 to Time 2 & $28 \%$ & $22 \%$ \\
\hline & Time 2 to Time 3 & $18 \%$ & $22 \%$ \\
\hline Indirect Action & Time 1 to Time 2 & $28 \%$ & $31 \%$ \\
\hline & Time 2 to Time 3 & $23 \%$ & $21 \%$ \\
\hline Prosocial Behavior & Time 1 to Time 2 & $28 \%$ & $27 \%$ \\
\hline & Time 2 to Time 3 & $19 \%$ & $23 \%$ \\
\hline Asocial Behavior & Time 1 to Time 2 & $24 \%$ & $26 \%$ \\
\hline & Time 2 to Time 3 & $22 \%$ & $16 \%$ \\
\hline
\end{tabular}

